\title{
How Do People Search Information on Content and Sources? Integrating Source Search in Information Boards
}

\author{
Leonie Aßmann*, Holger Futterleib*, Tilmann Betsch, Eva Thomm and Johannes Bauer \\ University of Erfurt
}

\begin{abstract}
Author Note
* The authors contributed equally to the development of the paradigm and the realization of the pilot study.

Declarations of interests: none.

Correspondence concerning this article should be addressed to

Leonie Aßmann, University of Erfurt, Nordhäuser Str. 63, 99089 Erfurt.

Phone: +493617372224

E-Mail: leonie.assmann@uni-erfurt.de
\end{abstract}

Acknowledgements.

We would like to thank Anna Lang for helpful comments on this manuscript and Heather Fiala for copy-editing. 


\title{
INTEGRATING SOURCE SEARCH IN INFORMATION BOARDS
}

\begin{abstract}
Information forms the basis for beliefs, judgements, decision making, and behavior.
\end{abstract} Nowadays, the amount of information available is continually increasing. Still, the quality and credibility of the corresponding sources vary widely. Thus, to avoid making judgments and decisions on basis of biased information, the credibility of information and sources must be carefully evaluated. However, information regarding the source is often not immediately accessible and, instead, must be purposefully sought. The standard information board paradigm does not include such a source information search. Therefore, we investigated whether that paradigm can be extended with an active search of source information in order to investigate search behaviors with regard to content und source information. To do so, we presented participants with information boards on different topics from two domains (i.e., health and education). The boards contained a question to outline the topic of information search in addition to four related sources. For each source, we provided information on topicrelated expertise and potential conflicts of interest as well as content information regarding the question (i.e., pro and contra arguments). Information was hidden so that participants had to actively search the information. We were interested in the search start, search amount, differences in search between the domains and belief revision due to information search. Results show that participants primarily began information search with source expertise before continuing on to content information. In general, both content and source information were searched. Domain did not influence the start but the search amount—more information was searched on topics in the educational domain. In addition, search appeared to influence prior beliefs. For some topics, we observed changes in beliefs following information search. The findings indicate that our variations in the information board paradigm can be used to investigate content information search and source information search simultaneously.

Keywords: information search; information boards; sources 
INTEGRATING SOURCE SEARCH IN INFORMATION BOARDS

\section{How Do People Search Information on Content and Sources? Integrating Source Search in Information Boards}

Information forms the basis for beliefs, judgements, decision making, and behavior (Sinatra \& Lombardi, 2020; Wathen \& Burkell, 2002). Due to technological advances, a seemingly infinite amount of information is readily available on the internet. Especially when people are not familiar with a topic, they search information online (Taddicken, 2013). However, even if the information is easily accessible, the internet has increased the spread of all kinds of information, including information of questionable quality and doubtful origins. Since gatekeepers are missing, individuals need to select information carefully in order to avoid misinformation and deception (Sperber et al., 2010). This can be a challenging task, because one might not be expert enough to interpret the information retrieved correctly. Especially when searching for science-related information from domains such as health, finance or climate change, individuals may face complex contents that go beyond their everyday understandings. Often, information varies in complexity and format as well as in consistency — the information provided might be contradictory depending on the different sources. Hence, due to their own bounded understanding people often must judge not only the validity of information contents but also the credibility of the source forwarding the information (Barzilai et al., 2020; Bromme \& Goldman, 2014; Hendriks et al., 2015; Pornpitakpan, 2004; Rowley et al., 2015). Consequently, individuals must actively consider and evaluate information about sources (Braasch et al., 2013; Bråten et al., 2017; Stadtler \& Bromme, 2014) after searching that information.

\section{Environmental information search across research fields and in judgement and decision making specifically}

Information search in different environments has been investigated in many research fields with long and diverse research traditions such as psychology, economics, and 


\section{INTEGRATING SOURCE SEARCH IN INFORMATION BOARDS}

educational sciences. Also, numerous paradigms and methods have been used to investigate information search processes.

In judgement and decision making research, the information board paradigm (Payne, 1976; Payne et al., 1988) is one of the most prominent. Information boards were introduced by Payne and colleagues $(1976,1988)$ and can be used in the form of cards, a board game, or a computer game. The computer-based variants are also called MouseLab (Johnson et al., 1989; Payne et al., 1988) which are widely used (e.g., Bergert \& Nosofsky, 2007; Betsch et al., 2016; Lee et al., 2017; Söllner et al., 2014). Information boards allow to determine how information is searched on an individual level (Betsch et al., 2010). In general, they are displayed as a matrix consisting of different options, attributes (cues), consequences (cue values), and cue validities. Options are the alternatives between which people can choose. There are at least two different options (Pfister et al., 2017). Those options are either objects

(e.g., universities; books) or actions (e.g., getting vaccinated; drinking a third cup of coffee). The attributes or cues describe the options (e.g., location and quality of the universities) or make predictions about the options (e.g., good vs. bad). Consequences, in general terms, are the results that one will obtain by choosing an option. In the context of information boards, they are commonly called cue values and evaluate the options. The cue validities are usually the probability of right predictions or the relevance of the cue. They are either stated explicitly by default or have to be learned separately by the participants before the decision phase. Figure 1 illustrates an example of an information board. 


\section{Figure 1}

Example of an Information Board

\begin{tabular}{|l|c|c|}
\hline & City A & City B \\
\hline Soccer Team (80\%) & - & + \\
\hline State Capital (70\%) & + & - \\
\hline University (60\%) & + & - \\
\hline Industry (55\%) & + & - \\
\hline
\end{tabular}

Note. The information board was adapted from Söllner et al. (2013) and Gigerenzer \& Goldstein (1996). Participants must decide which of the two cities has more inhabitants (City-Size task, Gigerenzer et al., 1991). Cities A and B are the options. Soccer Team, State Capital, University and Industry are the cues (attributes), which describe the options by their presence or absence (i.e., + or -). Those descriptions are the cue values (consequences of each option). The cues differ in terms of their probabilistic relevance (provided as percentages), which are the cue validities.

All aspects within information boards can be manipulated: One can vary the number of options, number of attributes, appearance of consequences - e.g., icons (thumbs-up vs. thumbs-down), symbols (plus vs. minus), and single words (excellent vs. good vs. average vs. bad) - and the dispersion of cue validities. Commonly, search start, search amount, and specific search strategies are measured in addition to the option chosen. To measure the variables of information search, the cells of the matrix, which contain the consequences, are covered so that participants must actively search the information they are interested in by uncovering the corresponding cells.

Advantages of information boards. Information boards enable researchers to examine information search in a controlled environment. Only information that has actively been searched can be integrated in information processing (Willemsen \& Johnson, 2011). The order in which information have been accessed can be traced as well as how much information was searched in total. If one cell closes with the assessment of a new piece of information, it is even possible to investigate how many pieces of information have been 


\section{INTEGRATING SOURCE SEARCH IN INFORMATION BOARDS}

searched multiple times. In many everyday decisions, necessary information is not directly accessible. Therefore, the information search that is realized within information boards resembles the information search that must be conducted in real-life decision making. Additionally, various real-life situations can be modelled in information boards, such as looking for the best job applicant, choosing a car, renting a flat, deciding for a vacation resort, and many more.

Disadvantages of information boards. In information boards, information is highly structured. Thus, the context is pre-defined and contains a limited number of information, which might foster a more controlled form of information search (Glöckner \& Betsch, 2008; Norman \& Schulte-Mecklenbeck, 2010). Additionally, it does not necessarily reflect the complexity of real-life decision making. Further, the information provided are often binary predictions. So even when they are contradictory, the information does not necessarily need to be evaluated in detail to judge the credibility of the specific content. Another limitation of the paradigm is that information on sources is rare. Source information is only present in terms of cue validities. As discussed above, particularly in today's digital information environment, people need to be able to assess different aspects of a source (i.e., its reliability, accuracy and credibility). In information boards, cue validities are the only information about the cues. This means that the judgement of the sources can potentially be based on only a single piece of information that is already provided by default. Especially when information is sought online, information on the source must be actively searched in addition to content information, because it is often not directly available. In addition, the cue validities, which are commonly displayed as percentages, are source information that cannot be found in the real world where source information and its credibility judgement is based on factors such as expertise or trustworthiness. Though important, extensive source evaluation plays a minor role in the traditional information boards. Sources are not evaluated in detail but rather must 


\section{INTEGRATING SOURCE SEARCH IN INFORMATION BOARDS}

only be considered in terms of their probability of making a correct predication or evaluation. Thus, the external validity of the paradigm is limited.

\section{Integrating source information and contextualized cue values into the information board paradigm}

The focus of the information search process in judgement and decision making is on the content (typically a prediction) rather than the source of information (cue).

However, as mentioned before, searching and elaborating source information is also a relevant part of information processing. Since both processes - the search of content information and the search of source information — are important, we combined both in the present study. The goal was to design an information board that allows to study the active search for content and source information. We aimed to adapt the information boards by including the possibility to search for source information without losing the strengths of the existing paradigm. Subsequently, we examined how individuals search for content and source information when both kinds of information must be actively searched for informing themselves about controversial science-related topics by using the adapted information board. Specifically, we analysed where participants begin their information search as well as how many pieces of content and source information they search in order to inform themselves about controversial science-related topics.

In addition, we were interested in belief revision due to information search, because credibility judgements depend not only on characteristics of the content and source but are also influenced by characteristics of the receiver (Wathen \& Burkell, 2002) such as their prior beliefs (Bråten et al., 2011; Bråten et al., 2017) and familiarity with the topic (Barzilai et al., 2020; Bråten et al., 2011; McCrudden et al., 2016). 


\section{INTEGRATING SOURCE SEARCH IN INFORMATION BOARDS}

We addressed the following research questions:

- Where does the information search begin? Do participants begin with content or source information?

- Do participants search similar amounts of information on the source and information on the arguments?

- Does the search amount differ between the domains?

- Does the presentation of information during search change prior beliefs?

\section{Pilot Study}

\section{Method}

Sample. We aimed to test whether the new variant of the paradigm can be used to examine information search processes of content and source information simultaneously. Thus, we conducted the first study with a comparably small sample. We recruited 29 students ( $76 \%$ female; mean age $=21.41$ years, $S D=2.11$ ) from the University of Erfurt (mean semester $=3.55, S D=2.56)$. Participants were paid with a voucher of $4.20 €$ for the Campus café. Participation lasted approximately 30 minutes.

Design. We used a 2 (domain of science-related topic: education vs. health) x 10 (topic: five education topics vs. five health topics; see Table 1) x 4 (information category: expertise vs. interest vs. pro vs. contra) within-design. The dependent variables were the search start and the search amount. Additionally, we measured prior and posterior beliefs about the presented topic in order to scrutinize potential belief revision.

Paradigm. We adopted an information board paradigm normally used for studying information search in decision making (see Figure 1; Payne, 1976; Payne et al., 1988). It was combined with an active search of source information. To do so, we extended the provided information in terms of quantity and quality. The given cue validities, which are usually probabilistic information on the source, were replaced with information on the sources' 


\section{INTEGRATING SOURCE SEARCH IN INFORMATION BOARDS}

expertise and interests (= trustworthiness) in the form of texts. Thus, with this new variant, information can be searched in relation to not only the content but also the source. Another variation is the provided content information. In most studies on decision making, consequences (cue values) that evaluate the options are the information that can be searched. Typically, the cue values are binary predictions. In our study, we used content information-precisely, arguments in text format—concerning a given topic question. Accordingly, there is no decision on different options after information search — rather, the search goal is to obtain knowledge and make an informed judgement regarding the topic questions.

Material. Information boards were conducted for ten trials. Each trial had a new topic. We used two topic domains, specifically education and health, since the participants should be quite familiar with both domains. For each domain, five topics were chosen for which misconceptions and false beliefs are still common. The topics and specific statements are displayed in Table 1. Agreement to those statements was measured before and after information search on a 7-point Likert scale to capture participants' prior and posterior beliefs.

\section{Table 1}

Overview of Topics and Corresponding Statements.

\begin{tabular}{ll}
\hline Topic & Statement \\
\hline Class size & $\begin{array}{l}\text { „The reduction of class size has a positive impact } \\
\text { on the quality of classes.” }\end{array}$ \\
$\begin{array}{l}\text { Learning method for reading and } \\
\text { spelling }\end{array}$ & $\begin{array}{l}\text {,The instruction 'Schreiben nach Gehör' is } \\
\text { effective in teaching students how to write.” } \\
\text { Grade retention }\end{array}$ \\
"Grade retention is a helpful intervention to \\
support low achieving students.” \\
,The learning types of the students should be \\
considered and addressed during classes.” \\
Mobile phone radiation
\end{tabular}




\section{INTEGRATING SOURCE SEARCH IN INFORMATION BOARDS}

Canabinoids as pain treatments

ADHD treatment

Coffee consumption

Homeopathy
„Cannabinoids should be used as a therapy for chronic pain."

„Drugs against ADHD cause more harm than good."

„More than two cups of coffee a day is unhealthy."

„Homeopathic remedies should still be prescribed."

Note. Agreement with the statements ranged from 1 (totally disagree) to 7 (totally agree).

The information boards were implemented with cards and displayed as 4 x 5 matrices.

Sixteen of the 20 cards contained relevant information. They provided detailed information on the back of the cards regarding either the source or an argument. On the front, the category was displayed - that is, whether the card contained information on expertise, interest, pro or contra. The characteristics of expertise were factorized (expert vs. layperson) as well as those of interest (own vs. society). The exact wording changed with each topic. Participants needed to turn over the cards to read the information. The other four cards were placeholders to structure the matrix and stated the sources (i.e., Person A, Person B, Person, C, Person D). Figure 2 shows an example. 


\section{Figure 2}

The Trial of Class Size as an Example with All Card Backs Displayed.

\begin{tabular}{|c|c|c|c|c|}
\hline \multicolumn{5}{|c|}{ „Does the reduction of class size have a positive impact on the quality of classes?” } \\
\hline Expertise & Interest & Source & Pro & Contra \\
\hline $\begin{array}{l}\text { Person } A \text { is researcher in } \\
\text { the field of theology. }\end{array}$ & $\begin{array}{c}\text { Person A has primarily the } \\
\text { interest of the society to } \\
\text { the goal. }\end{array}$ & Person A & $\begin{array}{l}\text { As there are fewer } \\
\text { students in the class, less } \\
\text { teaching disruptions } \\
\text { occur. }\end{array}$ & $\begin{array}{l}\text { The influence of class size } \\
\text { on student learning is } \\
\text { small because there are } \\
\text { many other influencing } \\
\text { factors. }\end{array}$ \\
\hline $\begin{array}{l}\text { Person } B \text { is researcher in } \\
\text { the field of social science. }\end{array}$ & $\begin{array}{l}\text { Person B primarily aims at } \\
\text { the protection of the } \\
\text { society's interest. }\end{array}$ & Person B & $\begin{array}{l}\text { Students are more } \\
\text { motivated because it is } \\
\text { their turn more often. }\end{array}$ & $\begin{array}{l}\text { Regardless of the size of } \\
\text { the class, teachers can } \\
\text { influence the quality of the } \\
\text { lessons, as the materials } \\
\text { used are particularly } \\
\text { important. }\end{array}$ \\
\hline $\begin{array}{l}\text { Person } \mathrm{C} \text { is researcher in } \\
\text { the field of theology. }\end{array}$ & $\begin{array}{l}\text { Person C primarily aims at } \\
\text { the protection of his own } \\
\text { interest. }\end{array}$ & Person C & $\begin{array}{l}\text { Teachers can supervise } \\
\text { students more } \\
\text { individually because they } \\
\text { have fewer students to } \\
\text { look after. }\end{array}$ & $\begin{array}{l}\text { Also in large classes all } \\
\text { students can be involved, } \\
\text { as different teaching } \\
\text { methods can be used. }\end{array}$ \\
\hline $\begin{array}{l}\text { Person D is researcher in } \\
\text { the field of social science. }\end{array}$ & $\begin{array}{l}\text { Person D has primarily his } \\
\text { own interest to the goal. }\end{array}$ & Person D & $\begin{array}{l}\text { Students can get } \\
\text { involved better during } \\
\text { the lessons because } \\
\text { there are fewer students } \\
\text { in the class. }\end{array}$ & $\begin{array}{l}\text { Teachers do not take } \\
\text { advantage of small class } \\
\text { opportunities because } \\
\text { they do not adapt their } \\
\text { teaching methodology. }\end{array}$ \\
\hline
\end{tabular}

Note. On top the statement was displayed as a question that had the same wording as the rated statement during the questionnaire. The columns and rows varied with each trial. Only the column "Source" was fixed as the middle of the matrix in each trial.

Procedure. Data collection was realized in individual settings. A trained experimenter supervised each participant, explained the procedure of the study, and informed the participant that their hands would be video recorded for data analysis purposes. After obtaining informed consent, participants filled out a questionnaire asking for demographics. In addition, they received short texts introducing the topics. After each text, participants rated their prior belief about the statement related to the topic (e.g., statement for the topic of class size: „The reduction of class size has a positive impact on the quality of classes.”) and continued with the next topic. When they finished the questionnaire, the experimenter introduced the participant to the information board. To ensure that the participant understood the setting of the matrix, several comprehension questions were asked before beginning the ten trails. 


\section{INTEGRATING SOURCE SEARCH IN INFORMATION BOARDS}

In all trials the experimenter placed the cards - that formed the information board-in front of the participant. Figure 3 shows an example of an information board used in the study.

\section{Figure 3}

Picture of the Material Used in a Study Trial.

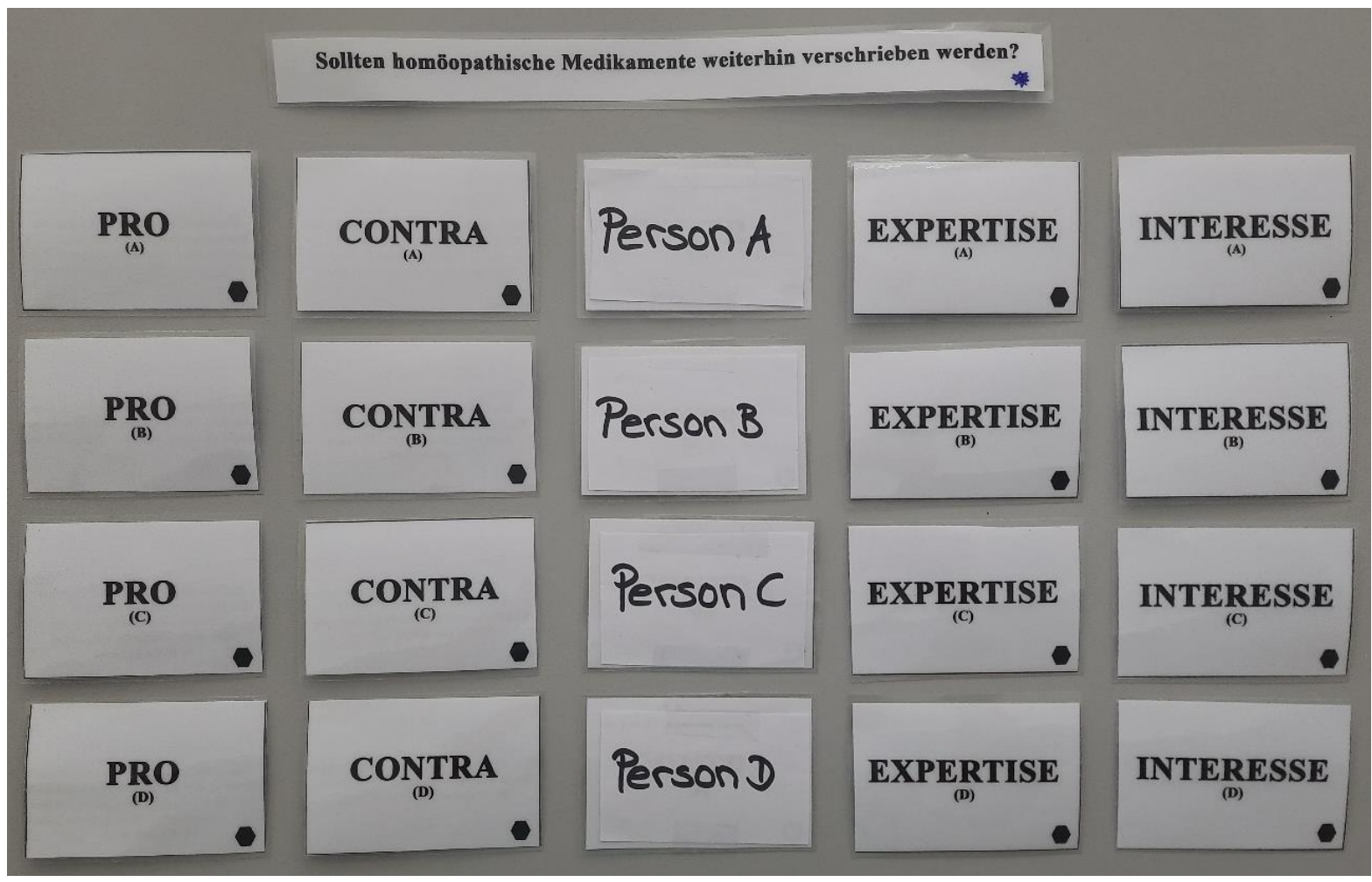

Note. The trial of homeopathy is shown with all cards' fronts displayed. The study was conducted in German.

The columns and rows of cards varied in a predefined random order around the "Person A-D"-cards for every participant and every trial. Participants were informed that they could turn over as many cards as they wished and as often as they liked. When participants finished their search, they rated their belief about the topic statement again and continued with the information board for the next topic. The order of domain was counterbalanced between participants. Thus, participants started either with the health domain or the education domain and then turned to the second domain block after five trials. The order of topics per 


\section{INTEGRATING SOURCE SEARCH IN INFORMATION BOARDS}

domain remained constant in each block. The experimenter was present in the room during the whole study to lay out the cards in every trial.

\section{Results}

We analyzed the information search behavior in a new variant of the information board paradigm. Each trial was videotaped and coded regarding the search start and the amount of information searched. Additionally, we investigated whether the presentation of arguments during the information search changed the prior belief.

Search Start. We aimed to examine where the information search started. Overall, participants began predominantly with the sources' expertise, independent of topic and domain $(M=74.5 \%$, across all ten topics $)$. Table 2 shows the total number of search starts according to topic and information category for both domains.

\section{Table 2}

Search Starts According to Topic and Category for Both Domains

\begin{tabular}{|c|c|c|c|c|c|c|}
\hline Topic & Domain & Expertise & Interest & Pro & Contra & Missing \\
\hline Class size & Education & 20 & 3 & 6 & 0 & 0 \\
\hline $\begin{array}{l}\text { Learning method for } \\
\text { reading and spelling }\end{array}$ & Education & 23 & 2 & 4 & 0 & 0 \\
\hline Grade retention & Education & 23 & 2 & 3 & 1 & 0 \\
\hline Learning types & Education & 21 & 0 & 4 & 3 & 1 \\
\hline Solution examples & Education & 23 & 2 & 4 & 0 & 0 \\
\hline $\begin{array}{l}\text { Mobile phone } \\
\text { radiation }\end{array}$ & Health & 19 & 3 & 5 & 2 & 0 \\
\hline Cannabinoids & Health & 24 & 2 & 3 & 0 & 0 \\
\hline ADHD treatment & Health & 18 & 5 & 4 & 1 & 1 \\
\hline Coffee consumption & Health & 22 & 5 & 2 & 0 & 0 \\
\hline Homeopathy & Health & 23 & 3 & 3 & 0 & 0 \\
\hline
\end{tabular}

Note. $N=29$. The missing value was due to the fact that one participant did not search for information on the respective topic.

There were no differences in participants' search start across topics from the domains of health and education. In the educational domain as well as in the health domain, the first 


\section{INTEGRATING SOURCE SEARCH IN INFORMATION BOARDS}

piece of information that the participant searched for was the expert status of the source. They began less often with information on the sources' interests $(M=9.3 \%)$, the pro argument $(M=13.1 \%)$, and the contra argument $(M=2.4 \%)$. Those differences in the distributions were significant $\left(\chi^{2}(3)>24.28\right.$, all $p$ 's $\left.<.001\right)$.

Search amount. Another focus was on the search amount. We investigated whether participants searched similar amounts of content and source information.

Table 3 displays the descriptive data on the information searched according to information category as well as averaged within and across domains. Participants searched more information on content (pro arguments and contra arguments) than source (expertise and interest). In addition, participants searched information about source interests least often as compared to any other category. To directly compare the search of content information and source information, we conducted a $t$-test with mean frequencies summed across categories. Participants searched content information $(M=6.42, S D=1.65)$ significantly more often than source information $(M=5.71, S D=1.45), t(28)=2.25, p=0.03$.

\section{Table 3}

Average Information Searched Across Domains and Overall.

\begin{tabular}{lcccc}
\hline & & Health & Education & Overall \\
& Category & $M(S D)$ & $M(S D)$ & $M(S D)$ \\
\hline Source information & Expertise & $3.59(0.87)$ & $3.59(0.86)$ & $3.59(0.87)$ \\
& Interest & $2.03(1.45)$ & $2.22(1.52)$ & $2.12(1.49)$ \\
Content information & Pro Argument & $3.11(1.04)$ & $3.33(0.96)$ & $3.22(1.00)$ \\
& Contra Argument & $3.02(1.10)$ & $3.38(0.94)$ & $3.20(1.04)$ \\
\hline Overall & & $2.94(1.27)$ & $3.13(1.22)$ & $3.03(1.25)$ \\
\hline
\end{tabular}

Note. Participants were presented with four pieces of information for each category per trial. Participants did not need to examine all pieces of information but could search as much information as they desired.

When examining the domains, the search amount also differs: in trials with health topics, participants looked up less information in general than in trials with educational 


\section{INTEGRATING SOURCE SEARCH IN INFORMATION BOARDS}

topics. We conducted a repeated-measures ANOVA with the dependent variable amount of information searched and the within-participants factors category of information searched and domain. We found a significant main effect for domain, $F(1,28)=4.95, p=.034, \eta^{2}{ }_{G}=.01$, and information category, $F(1.8,50.4)=28.20, p<.001, \eta^{2} \mathrm{G}=.26$. There was no significant interaction effect, $F(1.52,42.52)=1.79, p=.186, \eta^{2}{ }_{\mathrm{G}}=.005$.

Beliefs. We examined whether the presentation of information during the search process changed prior beliefs and analyzed belief revision. Descriptive data of prior and posterior beliefs are displayed in Table 4. Results showed that the extent of belief but also belief revision depended on the topic. There were significant differences between the prior and the posterior belief for the topics learning types, solution examples, mobile phone radiation, cannabinoids as pain treatment, ADHD treatment, and coffee consumption according to pairwise comparisons with Bonferroni-adjusted $t$-Tests for dependent samples.

\section{Table 4}

Descriptive Data for Beliefs and Results of t-Tests for Belief Revision.

\begin{tabular}{lcccccc}
\hline \multicolumn{1}{c}{ Topic } & \multicolumn{2}{c}{ Prior } & \multicolumn{2}{c}{ Posterior } & \multicolumn{2}{c}{ Belief Revision } \\
\hline & $M(S D)$ & Range & $M(S D)$ & Range & $t$ & $p$ \\
\cline { 2 - 7 } Class size & $5.83(1.49)$ & $2-7$ & $5.83(1.17)$ & $2-7$ & .00 & 1.00 \\
$\begin{array}{l}\text { Learning method for } \\
\text { reading and spelling }\end{array}$ & $3.28(1.58)$ & $1-7$ & $3.00(1.39)$ & $1-6$ & 1.68 & .103 \\
Grade retention & $3.79(1.95)$ & $1-7$ & $3.76(1.81)$ & $1-7$ & .115 & .909 \\
Learning types & $5.45(1.92)$ & $1-7$ & $4.41(1.92)$ & $1-7$ & 5.68 & $<.001$ \\
Solution examples & $5.14(1.13)$ & $1-6$ & $4.62(1.32)$ & $1-7$ & 2.42 & .046 \\
Mobile phone radiation & $4.66(1.34)$ & $1-7$ & $4.03(1.43)$ & $1-7$ & 2.64 & .026 \\
Canabinoids as pain & $6.17(.97)$ & $3-7$ & $5.21(1.47)$ & $2-7$ & 3.58 & .001 \\
treatment & & & & & & \\
ADHD treatment & $3.66(1.74)$ & $1-7$ & $4.17(1.67)$ & $1-7$ & -2.10 & .045 \\
Coffee consumption & $3.97(1.50)$ & $1-7$ & $3.07(1.28)$ & $1-6$ & 4.11 & $<.001$ \\
Homeopathy & $4.07(1.93)$ & $1-7$ & $4.38(1.94)$ & $1-7$ & -1.36 & .184 \\
\hline
\end{tabular}

Note. $N=29 . d f=28$. The $p$-values are Bonferroni-adjusted. 


\section{INTEGRATING SOURCE SEARCH IN INFORMATION BOARDS}

\section{Discussion}

We conducted this study based on the assumption that search for both content information and source information are important. The goal of the study was to examine whether the information board paradigm used in judgement and decision research (Payne et al., 1988) can be extended by integrating a search of source information. Designing and implementing such boards, we investigated participants' search start and search amount in order to make informed judgements about science-related topics. Moreover, we examined whether the searched — and possibly new_ information elicited changes in participants' prior beliefs.

Our results show that, across all topics, participants primarily began their information search by uncovering information about source expertise. Thus, this information appears to be perceived as highly relevant and led the search for most participants. The focus during information search was on both content and source information. Nevertheless, a closer look showed that the search amount differs across the categories. In general, more content information was searched. In addition, we found that source interests appeared to be least relevant. Participants searched information on the sources' potential interests less than any other information category. Domain did not appear to influence the search start, but the search amount. Thus, more information was searched for educational topics.

Overall, this study provides evidence that the new variant of information boards are useful to investigate information search on content and source information in a reduced yet highly controlled manner. It is possible to integrate an active search for source information to examine both search processes simultaneously and still investigate all aspects of the search behavior (i.e., start, direction, pattern, amount; see Payne et al., 1988). Participants adapted to the enriched information boards and used all information categories provided in the matrix. The information on the source-which was the central integration within the new information 


\section{INTEGRATING SOURCE SEARCH IN INFORMATION BOARDS}

board variant — has also been accessed by the participants. Most of them even searched that information first. By replacing the cue validities with specific information on the sources' topic-related expertise and their potential conflicts of interests a more detailed evaluation of the source was possible. This can also provide the foundation for a better classification of contradictory information based on the source forwarding the information. Since the cue values have been provided as pro and contra arguments, participants could evaluate the content information also in greater detail and use a broader knowledge base to form their own judgements concerning the topic questions. Providing more than binary predictions created a more realistic information search environment. The extension of content information also allows to study the information search in the context of controversial science-related topics. A variation of topics between the trials enables researchers a broader investigation of differences in information search and a comparison of several domains. This also provides insights into potential influences of prior knowledge and beliefs. For example, it can be examined whether participants look for confirming information in accordance with their prior knowledge and beliefs.

Additionally, it can be investigated whether information search influences prior beliefs. We found belief revisions for six topics. When comparing the prior and posterior beliefs, we observed less strong posterior beliefs for most topics. Participants likely obtained new information during the search that contradicted their previous knowledge or assumptions. As a consequence, their prior belief was challenged and thus decreased toward the mean of the scale for the posterior measurement.

Further research is needed to support our findings. In future studies, participants should have the opportunity to search information and state their beliefs in a fully anonymous manner-not only during data analysis but also during data collection. The presence of the experimenter might have affected the search behaviour and influenced the assessment of 


\section{INTEGRATING SOURCE SEARCH IN INFORMATION BOARDS}

beliefs. This could be eliminated by conducting online studies with a computer-based version of the information boards. Besides, it is assumed that variations of the design provide additional insights in searching information. Varying the amount of information given, setting a search start by default, and staying within a single topic while using multiple specific statements are possible ways of adjusting the paradigm and addressing further research questions.

Conclusion. Overall, our findings show that it is possible to integrate an active search of source information in the information boards commonly used in judgement and decision making research. The paradigm allows one to investigate where the search begins and whether participants pay equal attention to content and source information as well as examine how these processes differ due to preexisting knowledge and prior beliefs, between various topics from several domains, and across diverse goals of information search, e.g., decision making, making an informed judgement, presenting a topic, etc. 


\section{References}

Barzilai, S., Thomm, E., \& Shlomi-Elooz, T. (2020). Dealing with disagreement: The roles of topic familiarity and disagreement explanation in evaluation of conflicting expert claims and sources. Learning and Instruction, 69, 101367. https://doi.org/10.1016/j.learninstruc.2020.101367

Bergert, F. B., \& Nosofsky, R. M. (2007). A response-time approach to comparing generalized rational and take-the-best models of decision making. Journal of Experimental Psychology: Learning, Memory, and Cognition, 33(1), 107-129. https://doi.org/10.1037/0278-7393.33.1.107

Betsch, T., Funke, J., \& Plessner, H. (2010). Allgemeine Psychologie für Bachelor: Denken Urteilen, Entscheiden, Problemlösen (2011st ed.). Springer.

Betsch, T., Lehmann, A., Lindow, S., Lang, A., \& Schoemann, M. (2016). Lost in search: (mal-)adaptation to probabilistic decision environments in children and adults. Developmental Psychology, 52(2), 311-325. https://doi.org/10.1037/dev0000077

Braasch, J. L., Bråten, I., Strømsø, H. I., Anmarkrud, Ø., \& Ferguson, L. E. (2013). Promoting secondary school students' evaluation of source features of multiple documents. Contemporary Educational Psychology, 38(3), 180-195. https://doi.org/10.1016/j.cedpsych.2013.03.003

Bråten, I., Stadtler, M., \& Salmerón, L. (2017). The role of sourcing in discourse comprehension. In M. F. Schober, D. N. Rapp, \& M. A. Britt (Eds.), The routledge handbook of discourse processes (pp. 141-166). Routledge, Taylor \& Francis Group. https://doi.org/10.4324/9781315687384-10

Bråten, I., Strømsø, H. I., \& Salmerón, L. (2011). Trust and mistrust when students read multiple information sources about climate change. Learning and Instruction, 21(2), 180192. https://doi.org/10.1016/j.learninstruc.2010.02.002

Bromme, R., \& Goldman, S. R. (2014). The public's bounded understanding of science. Educational Psychologist, 49(2), 59-69. https://doi.org/10.1080/00461520.2014.921572

Gigerenzer, G., \& Goldstein, D. G. (1996). Reasoning the fast and frugal way: Models of bounded rationality. Psychological Review, 103(4), 650-669. https://doi.org/10.1037/0033-295X.103.4.650 


\section{INTEGRATING SOURCE SEARCH IN INFORMATION BOARDS}

Gigerenzer, G., Hoffrage, U., \& Kleinbölting, H. (1991). Probabilistic mental models: A brunswikian theory of confidence. Psychological Review, 98(4), 506-528. https://doi.org/10.1037/0033-295x.98.4.506

Glöckner, A., \& Betsch, T. (2008). Multiple-reason decision making based on automatic processing. Journal of Experimental Psychology. Learning, Memory, and Cognition, 34(5), 1055-1075. https://doi.org/10.1037/0278-7393.34.5.1055

Hendriks, F., Kienhues, D., \& Bromme, R. (2015). Measuring laypeople's trust in experts in a digital age: The muenster epistemic trustworthiness inventory (meti). PLOS ONE, 10(10), e0139309. https://doi.org/10.1371/journal.pone.0139309

Johnson, E. J., Payne, J. W., Schkade, D. A., \& Bettman, J. R. (1989). Monitoring information processing and decisions: The Mouselab system. Unpublished manuscript, Center for Decision Studies, FuquaSchool of Business, Duke University, Durham, NC.

Lee, M. D., Blanco, G., \& Bo, N. (2017). Testing take-the-best in new and changing environments. Behavior Research Methods, 49(4), 1420-1431. https://doi.org/10.3758/s13428-016-0798-X

McCrudden, M. T., Stenseth, T., Bråten, I., \& Strømsø, H. I. (2016). The effects of topic familiarity, author expertise, and content relevance on norwegian students' document selection: A mixed methods study. Journal of Educational Psychology, 108(2), 147-162. https://doi.org/10.1037/edu0000057

Norman, E., \& Schulte-Mecklenbeck, M. (2010). Take a quick click at that! Mouselab and eye-tracking as tools to measure intuition. In A. Glöckner \& C. Witteman (Eds.), Foundations for tracing intuition: challenges and methods (pp. 24-44). Psychology Press.

Payne, J. W. (1976). Task complexity and contingent processing in decision making: An information search and protocol analysis. Organizational Behavior and Human Performance, 16(2), 366-387. https://doi.org/10.1016/0030-5073(76)90022-2

Payne, J. W., Bettman, J. R., \& Johnson, E. J. (1988). Adaptive strategy selection in decision making. Journal of Experimental Psychology: Learning, Memory, and Cognition, 14(3), 534-552. https://doi.org/10.1037/0278-7393.14.3.534

Pfister, H.-R., Jungermann, H., \& Fischer, K. (2017). Die Psychologie der Entscheidung: Eine Einführung (4th ed.). Springer-Verlag. https://www.springer.com/de/book/9783662530375 https://doi.org/10.1007/978-3-662$53038-2$ 


\section{INTEGRATING SOURCE SEARCH IN INFORMATION BOARDS}

Pornpitakpan, C. (2004). The persuasiveness of source credibility: A critical review of five decades' evidence. Journal of Applied Social Psychology, 34(2), 243-281. https://doi.org/10.1111/j.1559-1816.2004.tb02547.x

Rowley, J., Johnson, F., \& Sbaffi, L. (2015). Students' trust judgements in online health information seeking. Health Informatics Journal, 21(4), 316-327. https://doi.org/10.1177/1460458214546772

Sinatra, G. M., \& Lombardi, D. (2020). Evaluating sources of scientific evidence and claims in the post-truth era May require reappraising plausibility judgments. Educational Psychologist, 55(3), 120-131. https://doi.org/10.1080/00461520.2020.1730181

Söllner, A., Bröder, A., Glöckner, A., \& Betsch, T. (2014). Single-process versus multiplestrategy models of decision making: Evidence from an information intrusion paradigm. Acta Psychologica, 146, 84-96. https://doi.org/10.1016/j.actpsy.2013.12.007

Söllner, A., Bröder, A., \& Hilbig, B. E. (2013). Deliberation versus automaticity in decision making: Which presentation format features facilitate automatic decision making? Judgment and Decision Making, 3(8), 278-298.

Sperber, D., Clément, F., Heintz, C., Mascaro, O., Mercier, H., Origgi, G., \& Wilson, D. (2010). Epistemic vigilance. Mind \& Language, 25(4), 359-393. https://doi.org/10.1111/j.1468-0017.2010.01394.x

Stadtler, M., \& Bromme, R. (2014). The content-source integration model: a taxonomic description of how readers comprehend conflicting scientific information. In D. Rapp \& J. L. G. Braasch (Eds.), Processing inaccurate information: theoretical and applied perspectives from cognitive science and the educational sciences. Boston Review.

Taddicken, M. (2013). Climate change from the user's perspective. Journal of Media Psychology, 25(1), 39-52. https://doi.org/10.1027/1864-1105/a000080

Wathen, C. N., \& Burkell, J. (2002). Believe it or not: Factors influencing credibility on the web. Journal of the American Society for Information Science and Technology, 53(2), 134-144. https://doi.org/10.1002/asi.10016

Willemsen, M. C., \& Johnson, E. J. (2011). Visiting the decision factory: Observing cognition with mouselabweb and other information acquisition methods. In M. SchulteMecklenbeck, A. Kuehberger, \& J. G. Johnson (Eds.), A handbook of process tracing methods for decision research: a critical review and user's guide. Psychology Press. 